\title{
Causes and nature of ice-sheet radio-echo internal reflections estimated from the dielectric properties of ice
}

\author{
Shuji Fujita and Shinji MaE \\ Department of Applied Physics, Faculty of Engineering, Hokkaido University, Sapporo 060, Japan
}

\begin{abstract}
The causes and nature of ice-sheet radio-echo internal reflections at deep layers in polar ice sheets are discussed, based on the dielectric properties of ice that have been measured at microwave frequency and radio frequency. The reflection cocflicients of electromagnetic waves in ice sheets due to two causes the change in permittivity induced by changes in crystal-orientation fabrics with depth, and changes in conductivity induced by changes in acidity with depth - wcrc derived rcspectively as a function of the frequency used in radar sounding and the temperature of ice, and both were compared quantitativcly. It is shown that at single-plane boundaries the reflcction coefficients due to the former cause are independent of frequency and tempcrature and that they are large enough to produce dominant internal reflections. In contrast, reflection coefficients due to the latter cause strongly depend on frequency and temperature. Since they are inversely proportional to the frequency, the latter cause can be dominant only when frequencies below about $60 \mathrm{MHz}$ are used. Examination of previous observational data has suggested that not only changes in acidity but also changes in crystal-orientation fabrics exist at depths corresponding to the dates of carlier volcanic eruptions.
\end{abstract}

\section{INTRODUCTION}

Radio-echo sounding (RES) of ice sheets is commonly used to investigate their internal structure and extent at frequencies between ten and several hundred $\mathrm{MH}_{z}$ (Robin and others, 1969; Bogorodsky and others, 1985). Changes in radar returns are caused by changes in the complex permittivity, $\varepsilon^{*}=\varepsilon^{\prime}-i \varepsilon^{\prime \prime}$, of layers of ice that comprise the ice sheets. Internal reflection horizons from within the ice sheets are often observed and several causes of these changes in the complex permittivity have been proposed. They are (1) density fluctuation, (2) changes in conductivity due to changes in acid concentration, and (3) changes in crystal-orientation fabrics (ice fabrics).

Density fluctuation can account for echoes at depths above about $1500 \mathrm{~m}$ (e.g. Parcn and Robin, 1975; Clough, 1977). Near the surface of ice sheets, ice lenses or more extensive featurcs of melt or depth hoar may cause changes in the permittivity and they are large enough to cause large reflections. However, since density contrasts between adjacent laycrs are smoothed out rapidly with increasing depth, the reflection horizons at deeper layers cannot be explained by this mechanism.

Several of the internal reflection horizons have been correlated to depths corresponding to the dates of large volcanic eruptions (Millar, 1981a, b). Hammer (1980) has shown that volcanic eruptions can produce an incrcase in the level of acidity of precipitation in polar regions for one or more years after the eruption. It is therefore tempting to assign changes in conductivity at radar frequencics that lead to internal reflection horizons to changes in acidity. Moore (1988) used changes in conductivity at low frcquency (LF) arising from the presence of both acid and salt impurities in an ice core to model the radar reflections that would come from an ice sheet from which the core was sampled. However, until recently, there has been no study on the effect of acid impurities on the elcctrical properties of ice at frequencies appropriate for RES. In order to investigate the effect of acid on the dielectric properties of ice at the microwave frequency, Fujita and others (1992) measured the complex permittivity of artificially grown polycrystalline ice containing strong acids $\left(\mathrm{H}_{2} \mathrm{SO}_{4}, \mathrm{HNO}_{3}\right.$ and $\left.\mathrm{HCl}\right)$ at $9.7 \mathrm{GH} z$. They found a linear relation between the complex permittivity and molarity of doped acid, which is independent of the kind of acid. Using this result and the LF-conductivity data of ice cores, Moore and Fujita (1993) compared the microwave and $\mathrm{LF}$ range conductivity in artificial and natural ice containing an acid impurity as a function of acid concentration and temperature. They found that the conductivity is almost the same at a microwave frequency and at an LF, and showed that there is no evidence of dielectric dispersion in conductivity arising from the presence of acid impurity between two frequency ranges. In addition, they found that the conductivity arising from the presence of acid is well fitted by a model where concentrated liquid acid at three grain boundaries forms a network, earlier proposed by Wolff and Paren (1984) as an 
explanation for d.c. conductivity of polar ice. Therefore, the properties of internal reflection can now be estimated as a function of acid concentration, frequency and temperature, because conductivity arising from the presence of acid is known as a function of them.

On the other hand, it is well known that ice fabrics in polar ice sheets change with depth. Harrison (1973) proposed an hypothesis that the variation of icc fabrics was one of the dominant causes of internal reflections. However, this was not supported, mainly because the dielectric anisotropy of ice, the difference between $\varepsilon_{\| c}$ : $\varepsilon^{\prime}$ parallel to the $c$ axis and $\varepsilon_{\perp c}, \varepsilon^{\prime}$ perpendicular to the $c$ axis, was unknown quantitatively at frequencies used in RES until recently. Clough (1977) estimated that sharp changes in crystal orientation may produce significant reflection coefficients if the anisotropy is as high as $1 \%$. Gow and Williamson (1976) showed examples of sharp changes in crystal orientation. They showed that the $c$ axes of ice containing volcanic ash are more tightly clustered around the vertical than those in enclosing ice layers in the Byrd Station core. Robin and Millar (1982) discussed the possibility that the presence of additional acid impurities in ice may change the mechanical properties of ice and that consequently the radio-echo layers may indicate the easy glide plane and hence the ice fabrics, as a possible explanation of the coincidence between the depths of internal reflection layers and the depths corresponding to the ages of the past volcanic eruptions.

Recently, Fujita and others (1993a) discovered that the dielectric anisotropy, $\Delta \varepsilon^{\prime}=\varepsilon_{\|_{c}}^{\prime}-\varepsilon_{\perp c}^{\prime}$, is 0.037 $( \pm 0.007)$ or $1.2 \%( \pm 0.2 \%)$ at $9.7 \mathrm{GHz}$. This value is large enough that changes in ice fabrics produce detectable internal reflections. Since Fujita and others (1993b) confirmed that $\Delta \varepsilon^{\prime}$ is of a similar magnitude at frequencies around $5 \mathrm{MHz}, \Delta \varepsilon^{\prime}$ is constant at frequencies used in RES. Using $\Delta \varepsilon^{\prime}$, Fujita and Mae (1993) calculated the dielectric permittivity tensors of ice in the ice sheet at Mizuho Station, Antarctica, using the icefabric data of the $700 \mathrm{~m}$ Mizuho ice core. They showed that the changes in permittivity tensors between adjacent depths were of the order of $0.1 \%$ and were large enough to produce dominant reflections.

In the light of new knowledge on the dielectric properties of ice, in this paper, we estimate the possible maximum reflection coefficients due to changes in ice fabrics and those due to changes in conductivity, as a function of frequency and temperature. The purpose of the estimation is to assess and to compare the significance of these two mechanisms. This leads to a conclusion that changes in ice fabrics are the predominant cause of the internal reflections at deep layers. In contrast, changes in conductivity can be one of the dominant causes only when frequencies below about $60 \mathrm{MHz}$ are used. When even lower frequencies are used, it is the predominant cause.

\section{REFLECTION DUE TO CHANGES IN CRYSTAL- ORIENTATION FABRICS}

\section{Reflection-coefficient calculation}

When electromagnetic waves are normally incident on a single layer which has thickness $l$, with bulk impcdance
$Z_{2}$, from a side of an enclosing layer with bulk impedance $Z_{1}$, the power-reflection coeflicient (PRC) has been given by Paren and Robin (1975) and Paren (1981) as follows

$$
\begin{aligned}
\mathrm{PRC} & =R_{\mathrm{s}} F \\
R_{\mathrm{s}} & =\left|\frac{Z_{1}-Z_{2}}{Z_{1}+Z_{2}}\right|^{2} \\
F & =4 \sin ^{2}\left(\frac{2 \pi l}{\lambda_{\mathrm{m} 1}}\right) .
\end{aligned}
$$

Here, $R_{\mathrm{s}}$ is the reflection coefficient at a single plane boundary. "The factor " $F$ " expresses the effect of interference between waves that are reflected at the upper boundary and lower boundary of the layer, $\lambda_{\mathrm{m}}$ is the wavelength in the ice. Since $F$ is a periodical function of $l$ and $\lambda_{\mathrm{m}}$, the PRC is also a periodical function of them. The properties of $R_{\mathrm{s}}$ are discussed first in this paper. The effect of $F$ is discussed later.

If the change in impedance is only due to a change in permittivity from $\varepsilon^{\prime}$ to $\varepsilon^{\prime}+\delta \varepsilon^{\prime}$, then $R_{\mathrm{s}}$ has been given by Paren and Robin (1975) and Paren (1981) as

$$
R_{s}=\left|\frac{\delta \varepsilon^{\prime}}{4 \varepsilon^{\prime}}\right|^{2} .
$$

PRC due to density fluctuation and changes in ice fabrics is calculated by Equations (la) and (2). If the change in impedance is only due to changes in dielectric loss, from $\tan \delta$ to $\tan \delta+\Delta(\tan \delta)$, then $R_{\mathrm{s}}$ has been given by Paren and Robin (1975) and Paren (1981) as

$$
R_{\mathrm{s}}=\left|\frac{\Delta(\tan \delta)}{4}\right|^{2}
$$

PRC due to changes in conductivity arising from the changes in acidity is calculated using Equations ( $1 \mathrm{a}$ ) and (3). A difference in phase by $\pi / 2$ occurs between the return signals of radio echo due to changes in conductivity in Equation (3) and those due to changes in permittivity in Equation (2) (Moore, 1988).

\section{Dielectric anisotropy of $\epsilon^{\prime}$}

Fujita and others (1993a) measured $\varepsilon_{\| c}^{\prime}$ and $\varepsilon_{\perp c}^{\prime}$ at $9.7 \mathrm{GHz}$ by the wave-guide method at temperatures between $32.5^{\circ}$ and $2.5^{\circ} \mathrm{C}$. The difference betwecn them that they found, i.e. dielectric anisotropy, was given by following equation

$$
\Delta \varepsilon^{\prime}=0.037( \pm 0.007)+0.00006( \pm 0.00009) T
$$

where $T$ is the temperature expressed in ${ }^{\circ} \mathrm{C}$. The tempcrature-dependence of $\Delta \varepsilon^{\prime}$ is negligibly small in the temperature range of the cryosphere. In addition, $\Delta \varepsilon^{\prime}$ is constant at frequencies used in RES.

The contribution of $\Delta \varepsilon^{\prime}$ to the changes in permitlivity in icc shects is formulated below. Fujita and Mae (1993) expressed the component of the dielectric permittivity tensor of polycrystalline ice as follows 


$$
\begin{gathered}
\varepsilon^{\prime}=\varepsilon_{\perp c}^{\prime}+\Delta \varepsilon^{\prime} D_{\mathrm{a}} \\
D_{\mathrm{a}}=\frac{1}{N} \sum_{j=1}^{N} \cos \theta_{j} .
\end{gathered}
$$

Here, $D_{a}$ was introduced as a factor that expresses the degree of the contribution of $\Delta \varepsilon^{\prime}$ to the component of the dielectric permittivity tensor. It was assumed that polycrystalline ice is composed of limitcd number, $N$, of crystal grains. We took the angle between the electric field vector of incident wave and the $c$ axis of the $j$ th grain as $\theta_{j}$. When electromagnetic waves reflect due to only the changes in ice fabrics, $R_{\mathrm{s}}$ becomes, using $\Delta \varepsilon^{\prime}$ and $D_{\mathrm{a}}$, from Equation (2) (Fujita and Mae, 1993)

$$
R_{\mathrm{s}}=\left|\frac{\Delta \varepsilon^{\prime} \delta D_{\mathrm{a}}}{4 \varepsilon^{\prime}}\right|^{2}
$$

where $\delta D_{\mathrm{a}}$ is the change of $D_{\mathrm{a}}$ at a boundary between adjacent ice layers.

\section{Changes in crystal-orientation fabrics}

In order to estimate possible $\delta D_{a}$ in Equation (7) and the thickncss of the layers in actual ice shects, we briefly introduce some examples of changes in ice fabrics with depth in actual polar ice sheets. An example is the study by Gow and Williamson (1976) in which they showed the variation of ice fabrics with depth in the Byrd Station ice core in Antarctica. They investigated the ice fabrics of six cloudy bands that contain visible volcanic glass shards and the ice fabrics of the enclosing ice, and they found that crystal axes tend to be more tightly clustered about the vertical in the cloudy bands than those in the enclosing ice at depths below $910 \mathrm{~m}$. The thicknesscs of cach band were in the range from $1 \mathrm{~mm}$ to $6 \mathrm{~cm}$. They reported that as many as 2000 individual bands were present in the Byrd Station ice cores, mostly in the zone from 1200 to $1800 \mathrm{~m}$ (Gow and Williamson, 1971). Because the crystal sizes of such layers were always very much smaller than those of the enclosing ice and had a fragmented appearance, thcy pointed out that such layers may also constitute zones of actual shear displacement in the ice sheet. The ice-fabric pattcrn that they observed in the cloudy bands is often called a vertical singlemaximum pattern that is formed in a high-shear zone (c.g. Russell-Head and Budd, 1979). Another example is the study by Thwaites and others (1984), who investigated the relationship between borehole-closure rate and ice fabrics in the ice corcs from Cape Folger, Antarctica. They found that closure rate was highly variable from one depth to another and was closely related to the fabrics of the ice. The zones at which the non-uniform closure occurred were $0.5-3 \mathrm{~m}$ wide. This indicates that the thicknesses of the laycrs in which the ice fabrics are uniform are of the same magnitude, at least at Cape Folger.

To calculate possible $R_{\mathrm{s}}$ from Lquation (7), the parameter $\delta D_{a}$ should be estimated. It is apparent that $\delta D_{\mathrm{i}}$ can easily be 0.1 , on the basis of the variations in the diclectric permittivity tensors of the Mizuho ice core given by Fujita and Mae (1993). A value of 0.1 mcans that $10 \%$ of $\Delta \varepsilon^{\prime}$ contributes to the changes in permittivity between adjacent layers. The possible upper limit of $\delta D_{\mathrm{a}}$ was cstimated as follows. If a randomly oriented ice fabric changes suddenly at a boundary to a vertical single-maximum pattern, $\delta D_{a}$ becomes $\frac{1}{3}$. Since a similar contrast in ice fabrics is seen in the Byrd Station ice core at a depth of $2006 \mathrm{~m}$, reported by Gow and Williamson (1976), this value seems to be the realistic upper limit of $\delta D_{\mathrm{a}}$ that exists in ice sheets. Therefore, $R_{\mathrm{s}}$ was estimated for values of $\delta D_{\mathrm{a}}$ between 0.1 and $\frac{1}{3}$. The calculated results are shown in Figure 1. In the figure, $R_{\mathrm{s}}$ is expressed in $\mathrm{dB}$. It is between -60 and $-70(\mathrm{~dB})$ and independent of both frcquency and temperature, since $\Delta \varepsilon^{\prime}$ is independent of them.

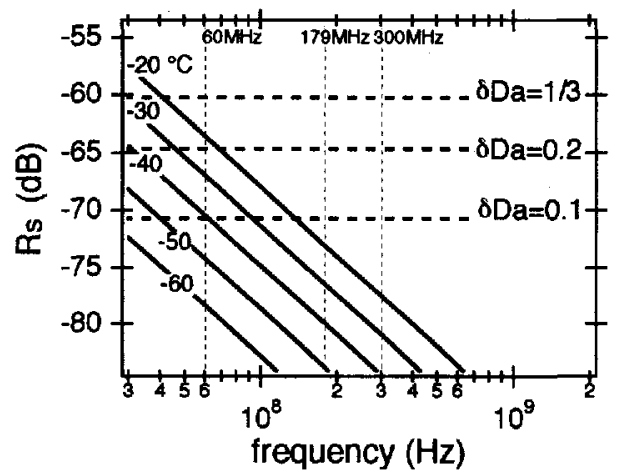

Fig. 1. The possible maximum reflection coefficients ( $R_{\mathrm{s}}$ ) due to changes in crystal-orientation fabrics (dashed bold lines) and those due to changes in conductivity (solid bold lines) in ice against frequency. The frequencies that were often used in radar sounding in Antartica by Millar (1981a,b) and by the Japanese Antartic Research Expedition are denoted by thin vertical dashed lines. Parameters used in estimations are described in the text.

\section{REFLEGTION DUE TO GHANGES IN CONDUCTIVITY}

\section{Conductivity arising from the presence of acid impurity}

Moore and Fujita (1993) rewrote the increase in $\tan \delta$ arising from the presence of acid impurity in acid-doped ice measured by Fujita and others (1992) at $9.7 \mathrm{GHz}$ as molar conductivity that means an increase in conductivity due to acid equivalent to 1 mole per litre, using the relation between conductivity, $\sigma_{\infty}$, and $\tan \delta, \sigma_{\infty}=$ $\varepsilon_{0} \varepsilon^{\prime} 2 \pi f \tan \delta$. Here, $\varepsilon_{0}$ is the permittivity in a vacuum. Since the molar conductivity was well fitted by the Arrhenius cquation by Moore and Fujita (1993), $\sigma_{\infty}$ can be written as

$$
\sigma_{\infty}=\sigma_{0} \exp \left(-\frac{E}{R T_{\mathrm{K}}}\right) \cdot C
$$

where $R$ is the gas constant, $E$ is an activation energy and $T_{\mathrm{K}}$ is absolute temperature. $C$ is the concentration of acid or hydrogen ions in ice in molarity. Based on the molar conductivity in the experimental results at $9.7 \mathrm{GH} z$, we obtain $\sigma_{0}=\exp (10.3)\left(\mathrm{S} \mathrm{m}^{-1} \mathrm{~mol}^{1}\right)$ and $E=18.8\left(\mathrm{~kJ} \mathrm{~mol}^{1}\right)$ at temperatures between $-5^{\circ}$ and 
$-30^{\circ} \mathrm{C}$. The increase in $\tan \delta$ arising from the acid impurity in ice, $\Delta(\tan \delta)$, is

$$
\Delta(\tan \delta)=\frac{\sigma_{\infty}}{\varepsilon_{0} \varepsilon^{\prime} 2 \pi f} .
$$

Substituting Equation (8) into $\sigma_{\infty}$ in Equation (9), Equation (9) becomes

$$
\Delta(\tan \delta)=\frac{\sigma_{0} \exp \left(-E / R T_{K}\right)}{\varepsilon_{0} \varepsilon^{\prime} 2 \pi f} C .
$$

$R_{5}$ is calculated as a function of change in acid concentration by substituting Equation (10) into Equation (3). Then Equation (3) is

$$
R_{5}=\left|\frac{\sigma_{0} \exp \left(-E / R T_{K}\right)}{\varepsilon_{0} \varepsilon^{\prime} 8 \pi f} C\right|^{2}
$$

Here, $R_{s}$ could bc cxpressed as a function of acid concentration, frequency and temperature.

\section{Changes in acid concentration}

In order to estimate possiblc $R_{5}$ from Equation (11), the parameter $C$ should be estimated. As a possible upper limit of $C$, we consider $7(\mu \mathrm{M})$ in Antarctica and $12(\mu \mathrm{M})$ in Greenland. The reason is as follows. In Antarctica, for example in the Byrd Station ice core, the levels of acidity peaks were $10 \sim 15$ ( $\mu$ eq. $\mathrm{H}^{+} \mathrm{kg}^{-1}$ ) (Hammer and others, 1985). The level of the acidity pcak in the Vostok ice corc and the South Pole ice core is of a similar magnitude (figures 3 and 4 in Legrand and others (1987)). In contrast, in Greenland, most of the acidity peaks in the Crête icc corc, Dye 3 ice core and Camp Century ice core were below 15 ( $\mu \mathrm{eq} . \mathrm{H}^{+} \mathrm{kg}^{+}$) but in some extreme cases the acidity reached as high as about 25 ( $\mu \mathrm{eq} . \mathrm{H}^{+} \mathrm{kg}^{-1}$ ) (figure 2 in Hammer (1980)). When the acid concentration is expressed in molarity, that is the unit $C$ in Equation (11), the upper limit roughly becomes $7(\mu \mathrm{M})$ in Antarctica and $12(\mu \mathrm{M})$ in Greenland, respectively. This conversion is based on the fact that most acid peaks in polar ice cores are a result of volcanic eruptions and are usually dominated by $\mathrm{H}_{2} \mathrm{SO}_{4}$. In polar ice, $\mathrm{H}_{2} \mathrm{SO}_{4}$ is considered to exist at three-grain boundaries (Wolff and Paren, 1984) as the liquid phase. In the liquid phase, only almost one hydrogen ion is dissociated from each

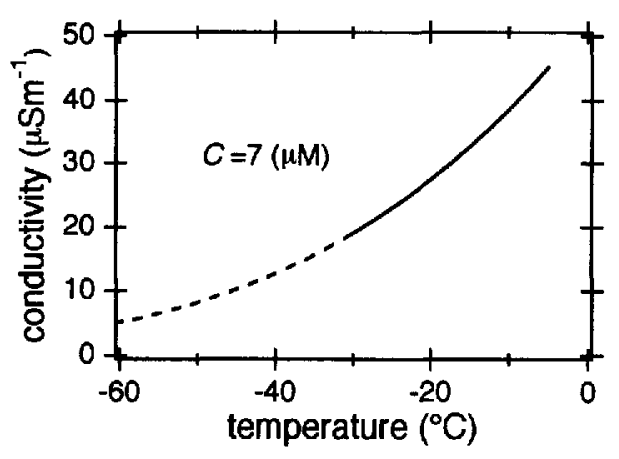

Fig. 2. Conductivity of ice containing acid of $7 \mu \mathrm{M}$, calculated using Equation (8). It is assumed that $7 \mu M$ is the approximate upper limit of acid concentration in acid peaks in the Antarctic ice sheet. molecule of $\mathrm{H}_{2} \mathrm{SO}_{4}$ and hydrogen ions dominate the conductivity in d.c., I.F and microwave frequencies (Moorc and Fujita, 1993). Therefore, $\mathrm{l}$ (eq. $\mathrm{H}^{+} \mathrm{kg}^{-1}$ ) is 0.46 (M). Considering the upper limit, $7(\mu \mathrm{M})$ in Antarctica and $12(\mu \mathrm{M})$ in Greenland, $7(\mu \mathrm{M})$ was used as $C$ for the calculation of $R_{s}$ in Equation (11). The estimated $R_{\mathrm{s}}$ is shown in Figure 1 for various temperatures between $-60^{\circ}$ and $-20^{\circ} \mathrm{C}$. If one considers $12(\mu \mathrm{M})$ as the upper limit in Greenland, $+4.5(\mathrm{~dB})$ should be added to the PRC in Figure 1. In the calculation, the conductivity with $C=7(\mu \mathrm{M})$ was calculated first using Equation (8). It is shown in Figure 2 as a function of temperature. Because the parameters $\sigma_{0}$ and $E$ in Lquation (8) were derived from experiments at temperatures between $5^{\circ}$ and $-30^{\circ} \mathrm{C}$ in Fujita and others (1992), the calculated valucs below $-30^{\circ} \mathrm{C}$ are extrapolated values.

\section{EFFEGT OF LAYER THIGKNESS}

Since $F$ is a periodical function of $l$ and $\lambda_{\mathrm{m}}$ as in Equation (1c), we must consider the effect of $F$ in discussing the PRC in Equation (1a). Figure 3 is the variation of $F$ as a function of them. Here, $F$ was calculated for various $l$ and was expressed in dB. From the figure, clearly $F$ is very small when $l$ is below the order of $1 \mathrm{~cm}$. When $l$ is the order of $10 \mathrm{~cm}, F$ increases with increasing frcquency. It reaches a maximum value, about $6(\mathrm{~dB})$, when $\lambda_{\mathrm{m}} / 4$ reaches $l$. Howcver, it suddenly decreases at a higher frequency and repeats increasing and decreasing. When $l$ is of the order of $1 \mathrm{~m}, F$ oscillates with increasing frequency. These analyses indicate that layers thicker than several centimetres are important for the internal reflections. The layer thickness can be investigated if we observe the frequency at which a sudden decrease in the signal occurs. If the layer thickness is greater than $1 \mathrm{~m}$, the signal repeats fading and reappearing with increasing frequency.

When the PRC is expressed in $\mathrm{dB}$, it is a summation of $R_{\text {s }}(\mathrm{dB})$ and $F(\mathrm{~dB})$. An example of the PRC due to two causes is shown in Figure 4. The parameters used in the calculation are typical ones in an inland region of the Antarctic ice sheet. This figure shows that the PRC duc to changes in permittivity increase with increasing frequency when $\lambda_{\mathrm{m}} / 4$ is smaller than $l$, and that the PRC due to changes in conductivity is constant.

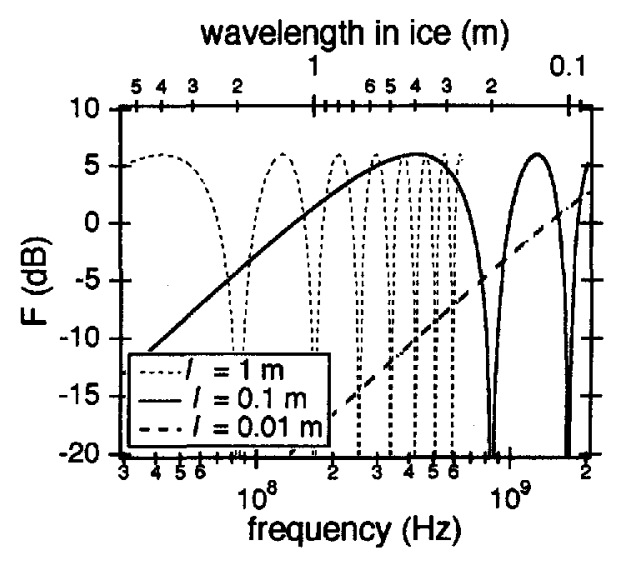

Fig. 3. $F(d B)$ in Equation (1c) as a function of frequency calculated for various layer thicknesses, $l$. 


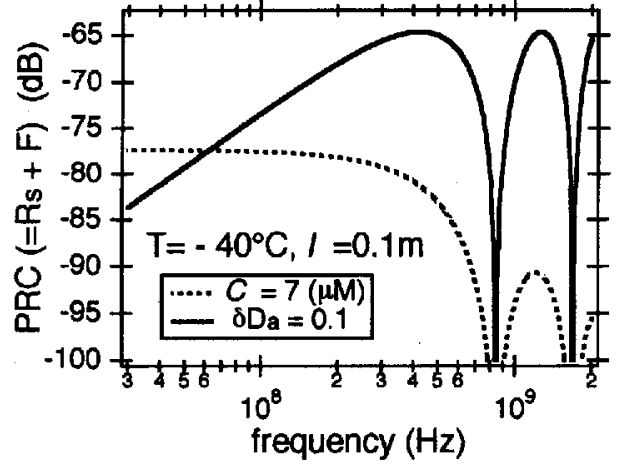

Fig. 4. $P R C(d B)$ as the summation of $R_{\mathrm{S}}(d B)$ and $F(d B)$. Typical parameters found in the Antarctic ice sheet are used for calculation.

\section{DISCUSSION}

\section{Frequency-dependence and temperature- dependence}

Now we can assess and compare the magnitude of the PRC and $R_{5}$ due to two mechanisms. Since $\Delta \varepsilon^{\prime}$ is independent of frequency and temperature, $R_{\mathrm{s}}$ due to changes in ice fabrics is independent of them. The upper limit of $R_{\diamond}$ is betwecn about -60 and $-70 \mathrm{~dB}$. These values are large enough to cause predominant reflections. In contrast, since changes in loss tangent due to changes in conductivity are inversely proportional to frequency in Equation (9), $R_{\mathrm{s}}$ is also inversely proportional to it. It strongly depends also on temperaturc. It has a similar magnitude to $R_{\mathrm{s}}$ due to changes in ice fabrics only when the frequencies are below about $100 \mathrm{MHz}$ as in Figure 1. These results strongly suggest that the predominant cause of the internal reflections is not changes in acidity but changes in ice fabrics, at least when frequencies about $100 \mathrm{MH}_{z}$ are used. When frequencies between about several tens of $\mathrm{MHz}$ and about $100 \mathrm{MH}_{\llcorner}$are used, two causes equally dominate internal reflections. If further lower frequencies are used, then the predominant cause is change in acidity. Considering the temperature-dependence, the results also suggest that only when changes in conductivity are the predominant cause, $R_{\mathrm{s}}$ is larger in Greenland than in the central part of Antarctica. The difference in the PRC, $R_{\mathrm{s}}$ and $F$ in both polar ice sheets is discussed later.

Inversely, the results mean that the dominant cause of reflection horizons can be investigated by observing frequency-dependence and temperature-dependencc of $R_{\mathrm{s}}$ or the PRC. If there are two kinds of reflection horizon in ice sheets, due to permittivity and due to conductivity, the dependence on frequency will be different from each other. If the acid concentration in ice sheets and the mechanical properties of ice (hence ice fabrics) are correlated as has been discussed by Robin and Millar (1982), the contribution of both causes in single layers can be analysed by investigating the frequency-dependence of $R_{3}$ or the PRC. Such analyses will provide information of the relation between the changes in acidity and ice fabrics in single layers. 'Therefore, analysis of multi-frequency RES data will provide further information about the internal reflection layers and the internal structure of the ice sheets.

\section{Examination of previously published RES data}

The difference in PRC in both polar ice sheets

In the light of new knowledge on the causes and the nature of the internal reflections, we review RES data that have been published so far. To discuss the predominant cause of internal reflections, it is important to compare $R_{\mathrm{s}}$ and the PRC that were observed under different temperature conditions. A good example is the difference in the PRC in the Antarctic ice sheet and in the Greenland ice shect found by Millar (1982). He found that the PRC at Crête in Greenland was typically 10 $20 \mathrm{~dB}$ greater than the PRG at several sites in East Antarctica. The frequency he used was $60 \mathrm{MHz}$.

To estimate the difference in $R_{\mathrm{s}}$ in both polar ice shects from the difference in PRC, we should first consider $F$ in both polar ice sheets. Since $F$ is a function of $l$, we should consider the difference in $l$ between both ice sheets. If we consider the difference in the annual layer thickness between both ice sheets, assuming that the thicknesses of the reflection layers are of the order of the annual accumulation rate, $F$ in Greenland is $7.6 \sim 20.4(\mathrm{~dB})$ larger than those in Antarctica. Table 1 shows the factor $F$ when the annual accumulation rate is taken as $l$. The annual accumulation rate at each site is cited from Ocschger and Langway (1989).

The assumption that we used is based on the observation by Millar (1981a, b) that the depths of the internal reflection layers are highly correlated with depths corresponding to the dates of past large volcanic eruptions. Since Hammer (1980) found that volcanic eruptions can produce an increased level in the acidity of precipitation in polar regions 1 or more years after the eruption, thicknesses of the layers containing acid impurity are of the order of the annual accumulation rate.

The calculated difference in $F$ agreed well with the difference in the PRC quantitatively. This coincidence means that $R_{\mathrm{s}}$ is almost the same for both ice sheets. This result is very important, because $R_{\mathrm{s}}$ is almost the same in spite of the temperature conditions and the concentration

Table $1 . F(d B)$ calculated from the annual accumulation rate of both ice sheets

Annual $F^{*}$

accumulation rate

$\mathrm{m}$

$\mathrm{dB}$

$\begin{array}{llr}\begin{array}{llr}\text { Grcenland } \\ \text { Crête }\end{array} & 0.28 & +1.4 \\ \text { Antarctica } & & \\ \text { Vostok } & 0.025 & -19.0 \\ \text { South Pole } & 0.08 & -8.9 \\ \text { Dome C } & 0.037 & -15.6 \\ \text { Byrd Station } & 0.11 & -6.2\end{array}$

${ }^{*} f=60 \mathrm{MHz}, \lambda_{\mathrm{m}}=2.8 \mathrm{~m}$ 
of acid in the acidity peak being different for both polar ice sheets. Therefore, this result suggests that conductivity was not the predominant cause of internal reflection even when $60 \mathrm{MHz}$ was used. If the predominant cause of internal reflections is changes in conductivity, differences in the acidity peak, $12 \mu \mathrm{M}$ and $7 \mu \mathrm{M}$, between Greenland and Antarctica, this should cause a difference in the $R_{\mathrm{s}}$ by about $4.5 \mathrm{~dB}$. The difference between the temperature in Greenland and in the central part of Antarctica by 20 $30^{\circ} \mathrm{C}$ should also cause a difference in $R_{\mathrm{s}}$ of about $10 \mathrm{~dB}$. Their summation, $14.5 \mathrm{~dB}$, should be observed as the difference in $R_{5}$ when changes in conductivity are a predominant cause. The lack of such a large difference in $R_{\mathrm{s}}$ means that internal reflections observed by Millar (1982) were not dominated by changes in conductivity in spite of the fact that it was observed at $60 \mathrm{MHz}$.

Correspondence between the layer depths in multi-frequency RES $A$ s for the multi-frequency RES, $z$-scope records from the South Pole and Dome $\mathrm{C}$ in Antarctica at 60 and $300 \mathrm{MHz}$ have been given by Millar (1981b) and Walford (1986). The records were ones used to investigate the correlation between the depths of the reflection layers and the dates of past volcanic eruptions (Millar, 1981a). Although the internal-layer records at $300 \mathrm{MHz}$ are affected by the spatial fading pattern, several layer echoes are seen to be common between the records for Dome $\mathrm{C}$ observed at $60 \mathrm{MHz}$ and at $300 \mathrm{MHz}$ at depths between 1 and $2 \mathrm{~km}$. Furthermore, considering the $R_{\mathrm{s}}$ at $300 \mathrm{MHz}$ in Figure 1, the cause of the layer echoes in the record at $300 \mathrm{MHz}$ should be attributed to changes in the ice fabrics. It is noteworthy that Millar (1981a) found a correlation between the depths of the reflection layers and the dates of past volcanic eruptions using the same records at $60 \mathrm{MHz}$. This fact and the interpretation of the $300 \mathrm{MHz}$ data suggest that the obscrved internal laycrs in the $300 \mathrm{MHz}$ records also have high correlation with the dates of past volcanic eruptions. This further suggests that changes in ice fabrics cxist at these depths. Since Millar (1981a,b) indicated that the PRC/age profiles have common features for layers observed at the South Pole, Vostok, Dome $\mathrm{C}$ and two other sites in East Antarctica in $60 \mathrm{MHz}$ records, the reflection layers due presumably to changes in ice fabrics, in the $300 \mathrm{MHz}$ record for Dome $\mathrm{C}$, may also exist at the other sites in East Antarctica.

The only scenario that consistently explains the above estimation, observations and discussions are as follows. Layers that contain matter originating from past volcanic eruptions have a different fabric pattern from the enclosing ice layers. It does not depend on whether the matter is visible or not because most acidity layers are invisible. This idea is supported by the fact that the acid peaks in the Byrd Station ice core were not found in association with the visible ash layers reported by Gow and Williamson (Hammer and others, 1985). The cause of changes in ice fabrics can be explained partly by the discussion by Robin and Millar (1982) that the presence of additional acid impurities in the ice may change the mechanical properties of the ice and that consequently the radio-echo layers may indicate the easy glide plane and hence the ice fabrics. The changes in ice fabrics predominantly caused internal reflections both at $60 \mathrm{MHz}$ and at $300 \mathrm{MHz}$, although changes in acidity might be one of the dominant causes at $60 \mathrm{MH}_{z}$. However, since the echoes are very clear at the crest of the ice shcet and around the summits of the ice sheet in the central part of East Antarctica (e.g. Robin and others, 1977; Millar, 1981b), around such places the formation process of the contrast of fabric patterns cannot be explained only by the shear motion of the ice sheet. Another mechanism that is related to grain growth may exist, such as, crystal size is highly corrclated with acidity (e.g. Langway and others, 1988).

\section{CONCLUSION}

The present study showed that possible maximum $R_{\mathrm{s}}$ and PRC are due to changes in crystal-orientation fabrics and are due to changes in acid concentration as a function of frequency and temperature. The estimations were based on the dielectric properties of ice measured in the laboratory. The former mechanism can produce predominant radio-echo reflections at deep layers in polar ice sheets. In contrast, the latter mechanism can be dominant at frequencies below about $60 \mathrm{MHz}$. The different frequency-dependence of different mechanisms means that the predominant cause of internal reflections can be finally determined by observing the frequency-dependence of the reflection coefficients. An examination of the RES data that have been published so far suggested that changes in ice fabrics exist at depths corresponding to the dates of past volcanic eruptions. If our discussions are entirely correct, the next interest is the quantitative relation between acidity, mechanical properties of ice, strain in each layer and the grain-growth process. This can be investigated quantitatively by careful investig-ations of the multi-frequency RES data and/or directly by icecore analysis. These studies are necessary for a correct understanding of the internal horizons and of the internal structure of polar ice sheets.

\section{ACKNOWLEDGEMENTS}

The authors thank an anonymous referee for his critical review from which the discussion has been improved significantly.

\section{REFERENCES}

Bogorodsky, V.V., C.R. Bentley and P.E. Gudmandsen. 1985. Radioglaciology. Dordrecht, Reidel.

Clough, J.W. 1977. Radio-echo sounding: Reflection from internal layers in ice sheets. 7. Glaciol., 18 78), 3-14.

Fujita, S. and S. Mae. 1993. Relation between ice-sheet internal radioecho reflections and ice fabric at Mizuho Station, Antarctica. Ann. Glaciol, 17, 269-275.

Fujita, S., M. Shiraishi and S. Mae. 1992. Measurement on the dielectric propcrtics of acid-doped ice at $9.7 \mathrm{GHz}$. IEEE Trans. Geosci. Remole Sensing, 30, 799803.

Fujita, S., S. Mae and T. Matsuoka. 1993a. Dielectric anisotropy in icc Ih at $9.7 \mathrm{CHz}$. Ann. Glaciol., 17, 276-280.

Fujita, S., T. Matsuoka, S. Morishima and S. Mae. 1993b. The measurement on the dielectric properties of ice at HF, VHF and microwave frequencies. In IGARSS'93 Symposium Digest, Volume III, $1258-1260$. 
Gow, A.J. and '1. Williamson. 1971. Volcanic ice in the Antarctic ice sheet and its possible climatic implications. Earth Ptanet. Sci. Lett. 13 1 ), 210-218.

Gow. A.J. and T. Williamson. 1976. Rheological implications of the structure and crystal fabrics of the West Antarctic ice sheet a revealed by deep core drilling at Byrd Station. CRREL Rep. 76-35.

Hammer, C. U. 1980. Acidity of polar ice cores in relation to absolute dating, past volcanism, and radio echoes. J. Glaciol., 25(93), 359-372.

Hammer, C. U., H. B. Clausen and C. C. Langway, Jr. 1985. The Byrd ice core: continuous acidity measurements and solid electrical conductivity measurements. Ann. Glaciol., 7, 214.

Harrison, C. H. 1973. Radio echo sounding of horizontal layers in ice J. Glaciol., 12,66), 383397.

langway, C. C. Jr, H. Shoji and N. Azuma. 1988. Crystal size and orjentation patterns in the Wisconsin-age ice from Dye 3, Grecnland. Ann. Glaciol., 10, 109-115.

Lcgrand. M., J. R. Petit and Y. S. Korotkevich. 1987. D.C. conductivity of Antarctic ice in relation to its chemistry. 7. Phys. (Paris), 48, Collog. C1, 605-611. (Supplément au 3.)

Millar, D. H. M. $198 \mathrm{la}$. Radio-echo layering in polar ice sheets and past volcanic activity. Nature, 292 5822), 44l-443.

Millar, D. H. M. $198 \mathrm{lb}$. Radio-cho layering in polar ice shects. (Ph.1) thesis, University of Cambridge.)

Millar, D.H.M. 1982. Acidity lcvels in ice sheets from radio echosounding. Ann. Glaciol., 3, 199-203.

Moore, J.C. 1988. Dielectric variability of a $130 \mathrm{~m}$ Antaretic ice core implications for radar sounding. Ann. Glaciol, 11, 95-99.

Moorc, J. C. and S. Fujita. 1993. Diclectric propertics of ice containing acid and salt impurity at microwave and low frequencies. 7 . Geophys. Res, $\mathbf{9 8}(\mathrm{B} 6), 9769-9780$.
Oeschger, H. and C. C. Langway, Jr. eds. 1989. The enzironmental record in glaciers and ice sheets. New York, John Wiley \& Sons.

Paren, J.G. 1981. Reflection coefficient at a dielectric interface. 7. Glaciol., 27 95$), 203-204$.

Paren, J.G. and G. de Q. Robin. 1975. Internal reflections in polar ice shccts. 7. Glaciol., 14(7l), 251-259.

Robin, G. deQ and D. H. M. Millar. 1982. Flow of ice sheets in the vicinity of subglacial peaks. Ann. Glaciol., 3, 290-294

Robin, G. de Q., S. Fvans and J.'T. Bailey. 1969. Interpretation of radio echo sounding in polar ice sheets. Phil. Trans. Roy. Soc. London, Ser. A, $265(166), 437-505$

Robin, G. de Q, D.J. Drewry and D. 'T'. Meldrum. 1977. International studies of ice sheet and bedrock. Phit. Trans. Roy. Soc. London, Ser. B, 279 $(963), 185-196$.

Russell-Hcad, D.S. and W.F. Budd. 1979. Ice-shect flow properties derived from bore-hole shear measurements combined with ice-core studies. 7. Glaciol, 2490), $117 \cdot 130$.

Thwaites, R.J., C.J.L. Wilson and A.P. McCray. 1984. Relationship between borchole closure and crystal fabrics in Antarctic ice core from Cape Folger., 7. Glaciol. 30 105), 171-179.

Walford, M. E. R. 1986. Scattering of radio waves by polar ice sheets. In Uscinski, B.J., ed. Wate propagation and scattering. Oxford, Clarendon Press, 261-279.

Wolff, E. W, and J. G. Paren. 1984. A two-phase model of electrical conduction in polar ice shects. 7. Genphy. Res., 89(B11), 9433-9438.

The accuracy of references in the text and in this list is the responsibility of the authors, to whom queries should be addressed. 